\title{
A New Device for Measuring Abdominal Wall Tension and Its Value in Screening Abdominal Infection
}

\author{
Hao Tang \\ Dong Liu \\ Yong Guo \\ Huayu Zhang \\ Yang Li \\ Xiaoyu Peng \\ Yaoli Wang \\ Dongpo Jiang \\ Lianyang Zhang \\ Zhengguo Wang
}

Wound Trauma Medical Center, State Key Laboratory of Trauma, Burns and Combined Injury, Daping Hospital, Army Medical University, Chongqing, 400042,

People's Republic of China
Correspondence: Zhengguo Wang; Lianyang Zhang Email hpzhangly@163.com; dpzhangly@163.com
Objective: This study is the largest clinical study of noninvasive Abdominal wall tension (AWT) measurement with a tensiometer to date. It also initially applies a polynomial regression equation to analyze the correlation between AWT measurement and intravesical pressure (IVP) measurement and remarkably finds interesting changes between different IVP intervals and AWT.

Methods: Critically ill patients who were treated in the intensive care unit (ICU) of Daping Hospital, Army Medical University, from August 30, 2018, to June 30, 2020, and met the inclusion criteria were prospectively included in this study. The patients were divided into an intra-abdominal hypertension group and a non-intra-abdominal hypertension group and an abdominal infection group and no abdominal infection group. AWT and IVP were measured at 9 points on the abdominal wall on the first day after admission to the ICU. The correlations between AWTs and IVP were analyzed, and the role of AWT in the diagnosis of complications of abdominal infection and the prediction of adverse prognosis were analyzed.

Results: A total of 127 patients were included. The average AWT and IVP were $2.77 \pm 0.38$ $\mathrm{N} / \mathrm{mm}$ and $12.31 \pm 7.01 \mathrm{mmHg}$, respectively, on the first day of admission. There was a positive correlation between AWT and IVP (correlation coefficient $\mathrm{r}=0.706, p<0.05$ ). The polynomial regression model was AWT $=-1.616 \times 10^{-3} \mathrm{IVP}^{2}+8.323 \times 10^{-2} \mathrm{IVP}+2.094$. The cutoff value of the sensitivity and specificity of AWT for the diagnosis of abdominal infection was $2.57 \mathrm{~N} / \mathrm{mm}$. Furthermore, AWT $=2.57 \mathrm{~N} / \mathrm{mm}$ had the best diagnostic efficiency, which was better than that of IAH and lactate.

Conclusion: There was a correlation between AWT and IVP. AWT measurement was helpful in the diagnosis of IAH and abdominal infection complications and can therefore serve as a new method for the clinical diagnosis of IVP and abdominal infection.

Keywords: intra-abdominal hypertension, abdominal wall tension, intra-abdominal pressure, abdominal compliance, abdominal infection

\section{Background}

The World Society on Abdominal Compartment Syndrome (WSACS) defines intraabdominal hypertension (IAH) as intra-abdominal pressure (IAP) $\geq 12 \mathrm{mmHg}$ and abdominal compartment syndrome (ACS) as abdominal pressure $\geq 25 \mathrm{mmHg}^{1,2}$ The incidence of IAH and ACS is $35 \%$ and $5 \%$, respectively, and the mortality rate is $38 \%-72 \% .^{2-4}$

At present, intra-abdominal pressure is usually measured by IVP after water injection via a Foley catheter. However, although this technique can measure IAP discontinuously, it is a cumbersome and minimally invasive procedure with 
a potential risk of infection. Therefore, it is necessary to develop a noninvasive, highly accurate and simple method to measure intra-abdominal pressure. ${ }^{2,5,6}$

Abdominal wall tension (AWT) refers to the tension of the abdominal wall, which is related to the structure and mechanical properties of the abdominal wall and plays a major role in abdominal compliance (AC). The AWT is affected by the contents of the abdominal cavity. When the contents of the abdominal cavity increase or the abdominal infection affects the peritoneum, the AWT increases. ${ }^{7-10}$ Thus, palpation of AWT is often used to infer the clinical diseases of abdominal hypertension or abdominal infection, but the disadvantage of this physical examination is that it is only qualitative and cannot be used for quantitative diagnosis. $^{11,12}$

According to the latest literature, noninvasive IAP measurement techniques can be generally classified into three categories: 1) strain gauge, respiratory inductance plethysmography (RIP) and tensiometer; 2) ultrasoundbased techniques (ultrasound tonometry, ultrasound assessment of the abdominal wall in combination with external pressure, ultrasound Doppler tonometry, laser-ultrasound, microwave reflection); and 3 ) bio-electrical impedance and microwave reflectometry. ${ }^{13}$ Currently, wireless motility capsules, digital image correlation, and laser ultrasound cannot be proposed as the best measurement techniques, mainly due to the lack of validation and clinical research. The RIP, strain gauge and Doppler ultrasound tonometry for IAP estimation are not reliable or accurate enough to be used in clinical practice. The tensiometry is compact, portable, easy to use and has the most data from previous studies, so the tension meter may be the best choice. ${ }^{13,14}$

We hope to use the novel noninvasive abdominal wall tension measurement device to quantitatively measure AWT and analyze its relationship with IVP (the gold standard for intra-abdominal pressure) and abdominal infection complications to provide a scientific basis for further research on the clinical value of AWT.

\section{Object and Method}

This is a prospective case cohort study conducted in the intensive care unit (ICU) of Daping Hospital, Army Medical University, from August 30, 2018, to June 30, 2020. The end point of the study was the discharge of patients from the ICU. The trial has been approved by the Ethics Committee of Daping Hospital, Army Medical University, and has been registered with the China Clinical Trial Center (Trial Registration Number:
ChiCTR190002562). The study was conducted in accordance with the Declaration of Helsinki.

\section{Research Subjects}

All consecutive admissions $(\mathrm{n}=153)$ between August 30, 2018, and June 30, 2020, were screened against the eligibility criteria. The inclusion criteria were as follows: (1) critically ill patients admitted to the ICU; (2) length of stay $>7$ days; (3) age $\geq 18$ years old; (4) high-risk factors for abdominal hypertension, such as mechanical ventilation, abdominal surgery, severe trauma, obesity (BMI $\geq 30 \mathrm{~kg}$ / $\mathrm{m}^{2}$ ), gastroparesis (gastric retention $>500 \mathrm{~mL}$ ), ileus (imaging confirmed slow intestinal peristalsis), ascites, hepatic insufficiency with ascites, cirrhosis with ascites and other abdominal conditions (peritonitis, abscess) of ascites, acidosis $(\mathrm{pH}<7.2)$, hypothermia (body temperature < $33^{\circ} \mathrm{C}$ ), high APACHE II score/SOFA score, massive fluid resuscitation (24-hour volume $>5 \mathrm{~L}$ ), coagulation disorder (platelet count $<55 \times 10^{9} / \mathrm{L}$ or activated partial thromboplastin time increased by 2 times or prothrombin time < $50 \%$ or international normalized ratio $>1.5),{ }^{15}$ sepsis (definition from the 2013 international guidelines for sepsis), shock or hypotension (systolic blood pressure $<90$ $\mathrm{mmHg}$ or more than $40 \mathrm{mmHg}$ lower than the average level); (5) placement of a urinary tube and have no contraindications for IVP measurement; and (6) signed informed consent. The exclusion criteria were as follows: (1) patients did not agree to have abdominal wall tension measurement; (2) the abdominal wall had a large area with defects or scars; (3) abdominal muscles were particularly developed, such as in athletes; (4) mental disorders; and (5) other conditions that were not suitable for measurement of AWT and IVP.

During the study period a total of 153 patients (across all specialties) were seen at the ICU. A total of 142 met the inclusion criteria, out of which 138 had consent given to take part in the study. Eleven withdrew consent halfway through the study. A total of 127 patients completed the study and their data were analyzed. (see Figure 1)

\section{Research Methods}

\section{Measurement Method of Abdominal Wall Tension} Composition of the AWT Measuring Device

A noninvasive multipoint abdominal wall tension measurement device (Chinese patent No. ZL 201510799207.4) was used. The device consisted of a high-precision resistance strain pressure transducer 


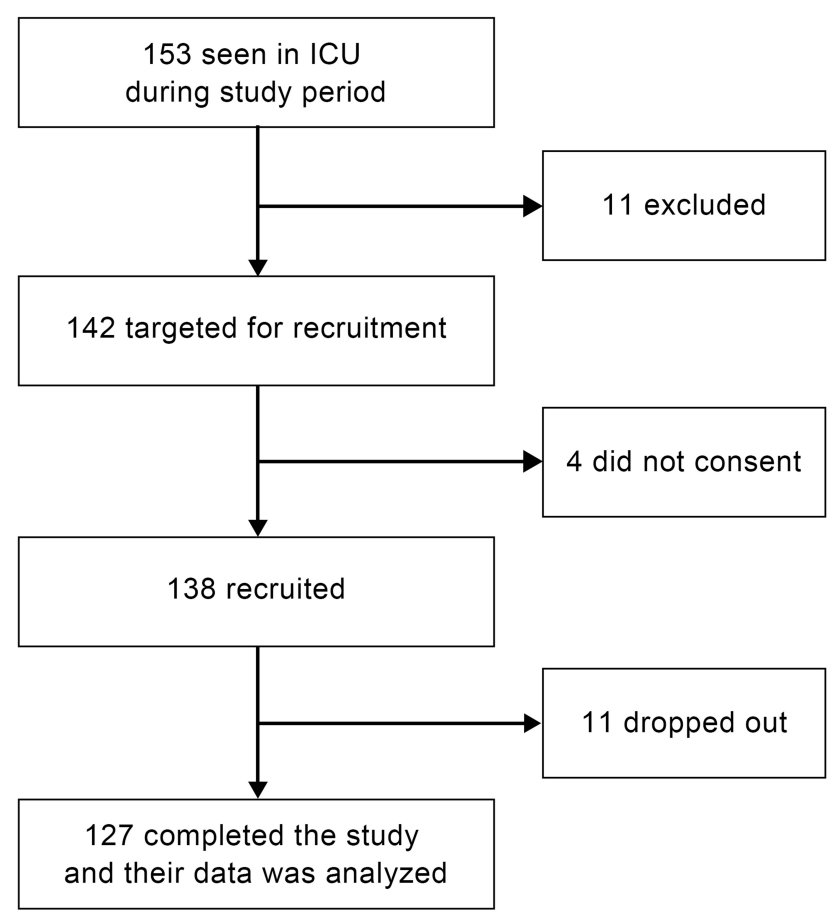

Figure I Recruitment scheme.

(JHBM-H3 pressure transducer from Bengbu Transducer System Engineering Co., Ltd, China), a displacement sensor with self-reset spring (KTR-A self-reset linear displacement sensor from Taizhou Quantum Electronic Technology Co., Ltd, China), and a data informationprocessing module (STMicroelectronicsSTM32 microcontroller, Italy; 24-bit AD conversion chip HX711, Avia Semiconductor Co., Ltd, China) (see Figure 2).

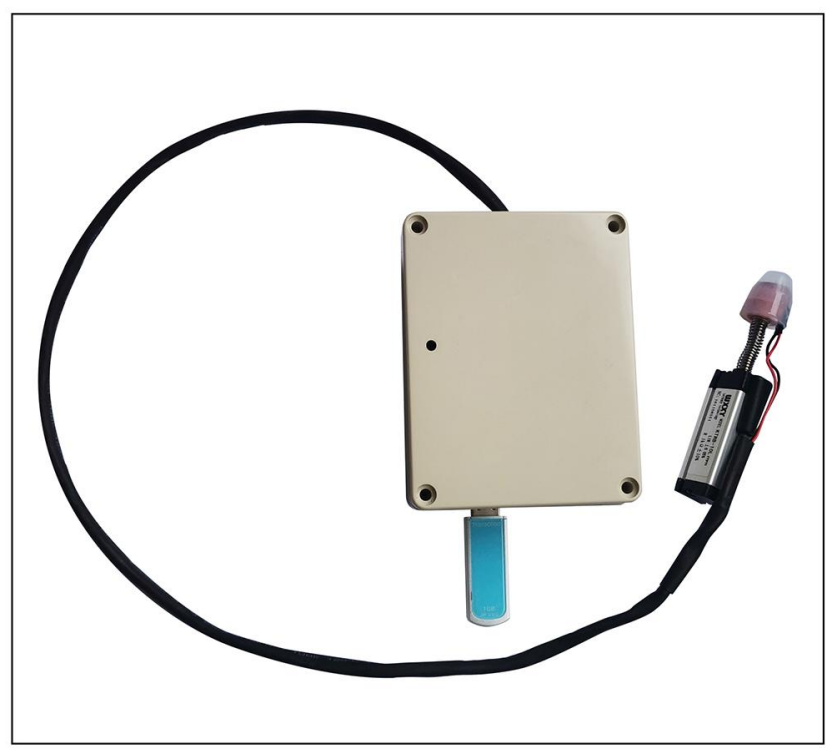

Figure 2 Appearance of the AWT measuring device.
Operating Principle of AWT Measurement

Pressure measurement: The membrane pressure transducer was located between the rubber head and the force application part and could accurately read the force value of the membrane transducer. The measurement range was $0-200 \mathrm{~N}$.

Displacement measurement: The displacement sensor used the analog/digital (A/D) converter chip HX711 to adjust and convert the sensor signal to obtain accurate data, with a measurement range of $0-50 \mathrm{~mm}$.

Technical parameters of the data collector for our equipment are as follows: the specified noise levels are general order \pm , with a signal-to-noise ratio (SNR) of 70 $\mathrm{dB}$, a sampling rate of $10 \mathrm{~Hz}$, and sampling bits of 12 .

Data information processing module: 100 values were collected in $1 \mathrm{~s}$, with a time interval of $0.01 \mathrm{~s}$. The pressure/displacement data were stored on a USB flash drive in text (txt) format.

Measurement Method of the AWT Measuring Equipment To ensure the consistency and accuracy of the AWT measurement method, we designated a dedicated person to perform AWT measurement and data collection. The AWT measurement equipment we used is simple, portable, and easy-to-operate equipment that can be used and completed well by one person.

To determine the standardization and consistency of AWT measurement points between different patients, we use human bone markers (xiphoid process, symphysis

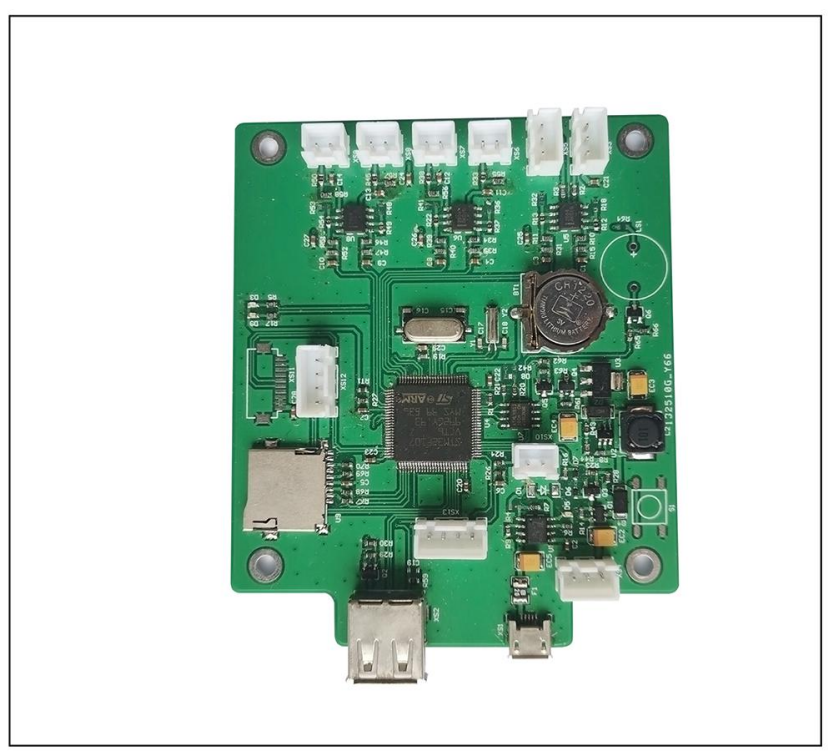


pubis) and fixed structures (navel) as the standardization points for AWT measurement points and follow the standard AWT measurement point determination method by using a marker to mark the surface of the patient's abdominal wall to ensure the standardization and consistency of the measurement points, as shown in Figure 3.

Patients were kept in a quiet state, in a supine position, with clothing, accessories and other coverings on the abdomen removed. For patients who were mechanically ventilated, the ventilator parameter positive end expiratory pressure (PEEP) was adjusted to $0 \mathrm{mmHg}$ before each measurement. After turning on the switch of the device, the pressure gauge was placed vertically on the surface of the measurement point of the abdominal wall, and the displacement sensor was pressed to the maximum displacement distance $(5 \mathrm{~cm})$ at a constant speed at the end of expiration. Each measurement lasted for 2-3 s, and the same method was used to measure each point approximately 20-30 times. Then, the device switch was turned off, and the measurement was completed.

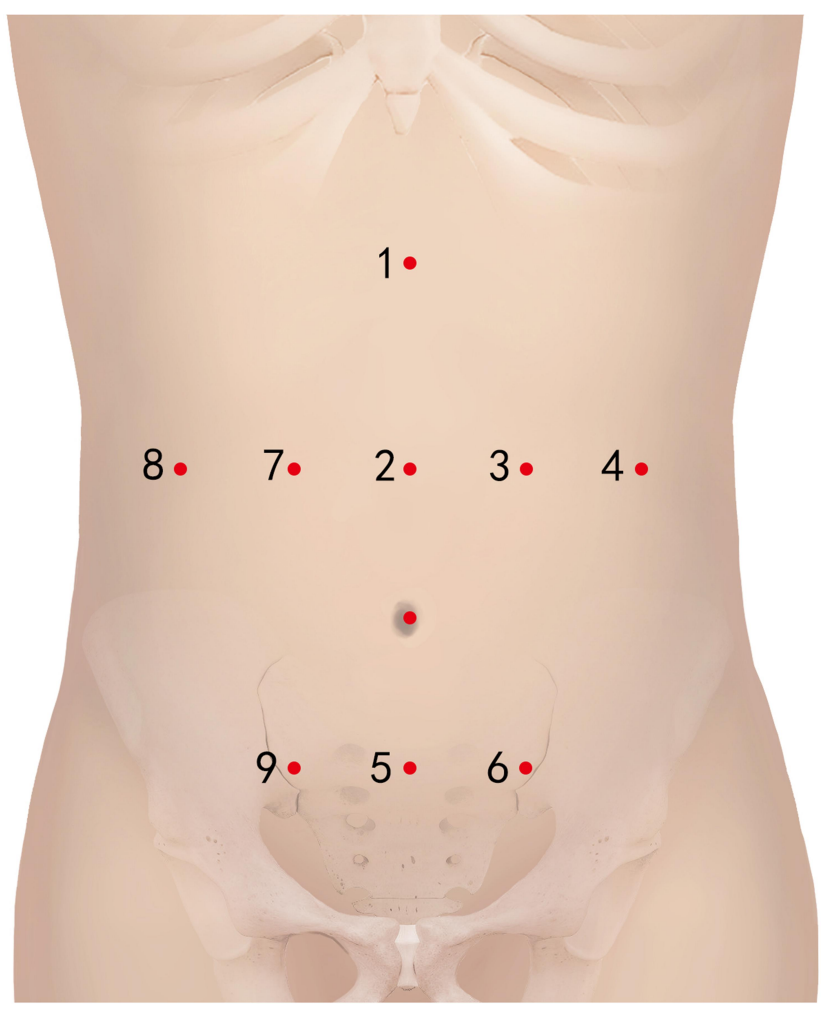

Figure 3 Body surface location of the 9 points on the abdominal wall. Point $1: 5 \mathrm{~cm}$ below the xiphoid process; Point 6: $5 \mathrm{~cm}$ to the left of Point 5. Point 2: $5 \mathrm{~cm}$ above the belly button; Point 7: $5 \mathrm{~cm}$ to the right of Point 2. Point $3: 5 \mathrm{~cm}$ to the left of Point 2; Point 8: $10 \mathrm{~cm}$ to the right of Point 2. Point 4: $10 \mathrm{~cm}$ to the left of Point 2; Point 9: $5 \mathrm{~cm}$ to the right of Point 5 . Point $5: 5 \mathrm{~cm}$ above the symphysis pubis.

\section{Analysis of the Raw AWT Data}

The data were analyzed and processed by MATLAB 2018a mathematical software (MathWorks, USA). AWT data are presented as a ratio curve of pressure/displacement, with the $\mathrm{X}$-axis as time and the $\mathrm{Y}$-axis as the pressure/displacement ratio. Three curves with uniform, stable and continuous waveforms were selected, and the average value of the maximum $\mathrm{Y}$ value of the three curves was taken as the final result of the AWT at each measurement point. The AWT curves of three patients with different intraabdominal pressures are shown in Figure 4.

\section{Intravesical Pressure (IVP) Measurement Method}

IVP was measured according to the guidelines of the WSACS in 2013. ${ }^{2}$ Malbrain's modified sterile IVP measurement device was used to connect to the patient's ureter. $^{6}$ The patient was in a supine and a relaxed state. After emptying the urine bag, $25 \mathrm{~mL}$ of normal saline was injected. The 0 mark of the measurement device was horizontal to the patient's midaxillary line, and the end expiratory reading was taken as the measurement result and converted into $\mathrm{mmHg}$. The measurement was conducted twice for each patient, and the average value was taken as the final result.

\section{Research Process}

All included patients were divided into an abdominal hypertension group and a nonabdominal hypertension group according to the value of intravesical pressure on the first day of ICU admission. The definition of abdominal hypertension was intravesical pressure $\geq 12 \mathrm{mmHg}$. ${ }^{2,4}$

According to whether there were abdominal infection complications (abdominal wall infection, diffuse peritonitis, localized peritonitis, retroperitoneal abscess, abdominal abscess), the patients were divided into an abdominal complication group and a nonabdominal complication group. Diagnosis of abdominal infection complications: A comprehensive diagnosis was made according to the clinical manifestations, physical examination and auxiliary examination (such as routine blood examination, calcitonin, blood culture, ascites culture, abdominal CT, ultrasound, etc.). The diagnostic criteria are provided in the consensus by the World Society of Emergency Surgery in 2016. ${ }^{16}$

Basic data (sex, age, BMI, reasons for admission to the ICU), clinical data (ISS, APACHE II SOFA score on the first day of ICU admission, procalcitonin, lactate, and C-reactive protein) and high-risk factors for intraabdominal hypertension (abdominal wall tension decreased, intestinal contents increased, abdominal 

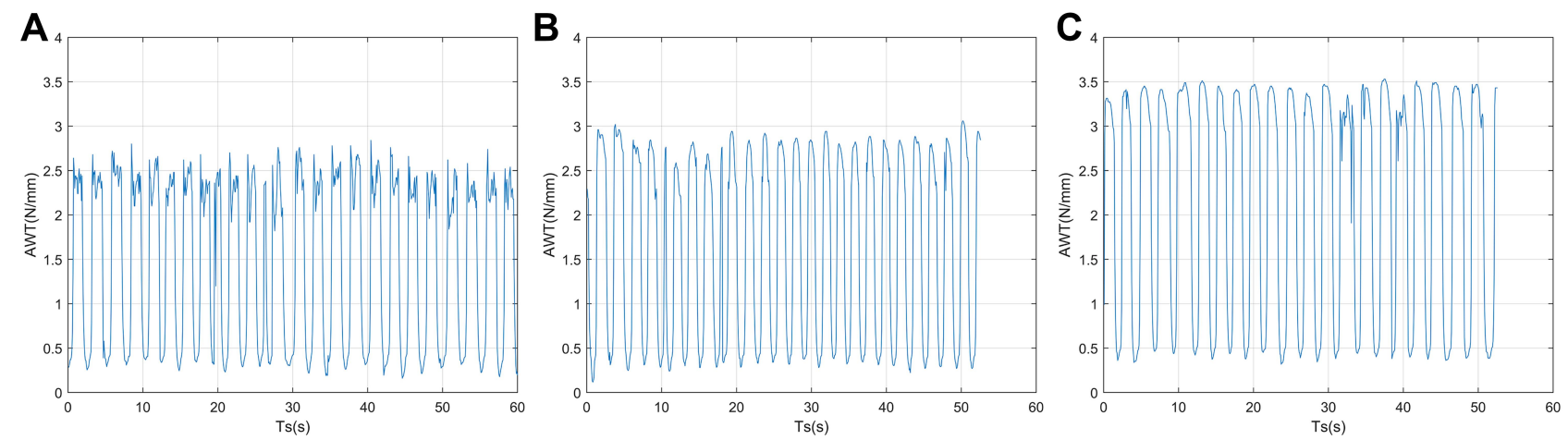

Figure 4 AWT curves of three patients with different intra-abdominal pressures. $(\mathbf{A}) \mathrm{IAP}=8 \mathrm{mmHg}, \mathrm{AWT}=2.59 \mathrm{~N} / \mathrm{mm} ;(\mathbf{B}) \mathrm{IAP}=12 \mathrm{mmHg}, \mathrm{AWT}=2.87 \mathrm{~N} / \mathrm{mm} ;(\mathbf{C}) \mathrm{IAP}=$ $22 \mathrm{mmHg}, \mathrm{AWT}=3.45 \mathrm{~N} / \mathrm{mm}$.

contents increased, capillary leakage or fluid resuscitationrelated factors) were collected.

The AWT at 9 points on the abdominal wall of the included patients was measured by the measurement device on the first day after admission to the ICU, and IVP was also measured. Statistical methods were used to analyze the AWT of the 9 points and the correlation between the average AWT of the 9 points and IVP. The diagnostic efficacies of the average AWT, lactate, IVP and average AWT + IVP in abdominal infection complications were analyzed.

\section{Statistical Analysis}

The mean and standard deviation (mean \pm STD) were used to describe the measurement data, and a $t$-test was used to compare the differences between groups. Measurement data were described as a percentage, and the chi-square test was used to compare the differences between groups. Pearson correlation was used to analyze the linear relationship between AWT and IVP. $p<0.05$ was considered to be statistically significant. The relationship between AWT and IVP was implemented with polynomial regression and a quadratic function for fitting. The area under the receiver operating characteristic (ROC) curve (AUC) was calculated, and the best diagnostic threshold was found by the Youden index. The sensitivity, specificity, positive predictive value and negative predictive value were calculated.

\section{Results}

\section{General Data and Clinical Data}

A total of 127 patients were analyzed, including 68 males $(53.54 \%)$, with an average age of $64.10 \pm 11.63$ years and an average BMI of $24.93 \pm 2.53 \mathrm{~kg} / \mathrm{m}^{2}$. The reasons for admission were as follows: Thirty-four cases $(26.77 \%)$ were admitted for medical reasons, and 93 cases (73.23\%) were admitted for surgical reasons. Among the patients with surgical reasons, 31 (24.41\%) were emergency patients, $31(24.41 \%)$ were selective operation patients, and $31(24.41 \%)$ were trauma patients.

There were 67 patients in the non-IAH group, including 34 males $(50.75 \%)$, with an average age of $46.06 \pm$ 10.88 years and BMI of $24.93 \pm 2.53 \mathrm{~kg} / \mathrm{m}^{2}$. There were 60 patients in the IAH group, including 34 males $(56.67 \%)$, with an average age of $46.15 \pm 12.51$ years and BMI of $25.31 \pm 2.43$.

On the first day of ICU admission, procalcitonin, AWT and IVP in the IAH group were $4.65 \pm 2.16 \mu \mathrm{g} / \mathrm{L}, 3.00 \pm$ $0.32 \mathrm{~N} / \mathrm{mm}$ and $8.52 \pm 3.84 \mathrm{mmHg}$, respectively, which were higher than those in the non-IAH group $(4.65 \pm 2.16$ $\mu \mathrm{g} / \mathrm{L}, 2.44 \pm 0.22 \mathrm{~N} / \mathrm{mm}$ and $7.06 \pm 2.97 \mathrm{mmHg}$, respectively, $p<0.05)$. The total length of hospital stay and ICU death in the IAH group were $17.25 \pm 5.32$ days and 19 cases $(31.67 \%)$, respectively, which were higher than those in the non-IAH group of $14.18 \pm 3.99$ days and 10 cases $(14.93 \%)$, respectively, $p<0.05$. The other results are shown in Table 1.

\section{High-Risk Factors for IAH in Patients}

The number of cases of laparotomy, obesity, intestinal obstruction, hepatic insufficiency with ascites and hypotension in the IAH group were $14(21.67 \%), 13$ (21.67\%), $13(21.67 \%), 17(28.33 \%)$ and $12(20.00 \%)$, respectively, which were higher than those in the non-IAH group ( 5 $(7.46 \%), 6(9.00 \%), 5(7.46 \%), 6(9.00 \%)$ and $3(4.48 \%)$, respectively, $p<0.05)$. There were no significant differences in other risk factors between the two groups (see Table 2). 
Table I Basic Data and Clinical Data of Patients

\begin{tabular}{|c|c|c|c|c|c|c|}
\hline & & All $(n=127)$ & $\begin{array}{l}\text { Non-IAH Group } \\
(n=67)\end{array}$ & $\begin{array}{l}\text { IAH Group } \\
(n=60)\end{array}$ & $T / \mathbf{X}^{2}$ & $p$ \\
\hline \multicolumn{2}{|c|}{ Male (n, \%) } & $68(53.54 \%)$ & 34 (50.75\%) & $34(56.67 \%)$ & 0.446 & 0.504 \\
\hline \multicolumn{2}{|c|}{ Age (years) } & $46.10 \pm 11.63$ & $46.06 \pm 10.88$ & $46.15 \pm|2.5|$ & -0.040 & 0.965 \\
\hline \multicolumn{2}{|c|}{ BMI $\left(\mathrm{kg} / \mathrm{m}^{2}\right)$} & $24.93 \pm 2.53$ & $24.60 \pm 2.59$ & $25.31 \pm 2.43$ & -1.590 & 0.115 \\
\hline \multicolumn{7}{|c|}{ Admission reason } \\
\hline \multicolumn{2}{|l|}{ Medical } & $34(26.77 \%)$ & 21 (3I.34\%) & $13(21.67 \%)$ & \multirow[t]{2}{*}{5.222} & \multirow[t]{2}{*}{0.1562} \\
\hline Surgical & $\begin{array}{l}\text { Emergency } \\
\text { Selective operation } \\
\text { Trauma }\end{array}$ & $\begin{array}{l}3 \text { I }(24.4 \text { I\%) } \\
3 \text { I }(24.4 \text { I\%) } \\
3 \text { I }(24.4 \text { I })\end{array}$ & $\begin{array}{l}17(25.37 \%) \\
18(26.87 \%) \\
\text { II (16.41\%) }\end{array}$ & $\begin{array}{l}14(23.33 \%) \\
13(21.67 \%) \\
20(33.33 \%)\end{array}$ & & \\
\hline \multicolumn{2}{|c|}{ ISS score $(n=3 \mid)$} & $22.7 I \pm 6.67$ & $19.09 \pm 5.74$ & $24.70 \pm 6.42$ & -2.410 & 0.022 \\
\hline \multicolumn{2}{|c|}{ APACHE II score } & $18.06 \pm 4.95$ & $|7.35 \pm 5.7|$ & $18.84 \pm 3.84$ & -1.700 & 0.092 \\
\hline \multicolumn{2}{|c|}{ SOFA score } & $5.28 \pm 1.70$ & $5.03 \pm 1.77$ & $5.57 \pm 1.59$ & -1.790 & 0.076 \\
\hline \multicolumn{2}{|c|}{ PCT (ug/L) } & $5.67 \pm 2.85$ & $4.65 \pm 2.16$ & $6.82 \pm 3.10$ & -4.53 & $0.000 *$ \\
\hline \multicolumn{2}{|c|}{ Lac (mmol/L) } & $3.80 \pm 2.37$ & $3.56 \pm 2.23$ & $4.06 \pm 2.51$ & -1.18 & 0.2406 \\
\hline \multicolumn{2}{|c|}{ CRP (mg/L) } & $10.38 \pm 5.47$ & $10.60 \pm 5.80$ & $10.14 \pm 5.12$ & 0.480 & 0.635 \\
\hline \multicolumn{2}{|c|}{ AWT (N/mm) } & $2.77 \pm 0.38$ & $2.44 \pm 0.27$ & $3.00 \pm 0.32$ & -8.720 & $0.000 *$ \\
\hline \multicolumn{2}{|c|}{ IVP (mmHg) } & $|2.3| \pm 7.0 \mid$ & $6.26 \pm 3.16$ & $19.06 \pm 2.43$ & -25.370 & $0.000 *$ \\
\hline \multicolumn{2}{|c|}{ Length of ICU stay (days) } & $7.75 \pm 3.47$ & $7.06 \pm 2.97$ & $8.52 \pm 3.84$ & -25.370 & $0.000 *$ \\
\hline \multicolumn{2}{|c|}{ Length of hospital stay (days) } & $15.63 \pm 4.90$ & $14.18 \pm 3.99$ & $17.25 \pm 5.32$ & -2.370 & $0.019 *$ \\
\hline \multicolumn{2}{|c|}{ ICU death rate $(n, \%)$} & 29 (22.83\%) & 10 (14.93\%) & $19(31.67 \%)$ & -3.640 & $0.000 *$ \\
\hline
\end{tabular}

Note: $*_{p}<0.05$.

Abbreviations: BMI, body mass index; ISS, injury severity score; APACHE, Acute Physiology, Age, Chronic Health Evaluation; SOFA, sequential organ failure; PCT, procalcitonin; Lac, lactate acid; CRP, C-reaction protein; AWT, abdominal wall tension; IVP, intravesical pressure; ICU, intensive care unit.

AWT at 9 Points on the Abdominal Wall, Average AWT and IVP on the First Day of

\section{Admission}

Among the 9 points on the abdominal wall, the positive correlations between Points 5 and 7 and the IVP were the best, with AWT values of $2.76 \pm 0.40 \mathrm{~N} / \mathrm{mm}$ and $2.78 \pm 0.40$ $\mathrm{N} / \mathrm{mm}$, respectively, and the correlation coefficients were 0.706 and 0.706 , respectively $(p<0.05)$. The polynomial regression models were AWT $=-2.399 \times 10^{-3} \mathrm{IVP}^{2}$ $+1.044 \times 10^{-1} \mathrm{IVP}+1.975$ and AWT $=-1.461 \times 10^{-3} \mathrm{IVP}^{2}$ $+8.135 \times 10^{-2}$ IVP+2.092, respectively.

The average AWT of all patients was $2.77 \pm 0.38 \mathrm{~N} /$ $\mathrm{mm}$, and IVP was $12.31 \pm 7.01 \mathrm{mmHg}$ on the first day of admission. The average AWT was positively correlated with IVP ( $r=0.706, p<0.05)$. The polynomial regression model resulted in a mean AWT $=-1.616 \times 10^{-3}$
IVP $^{2}+8.323 \times 10^{-2}$ IVP +2.094 (see Table 3, Figures 5 and 6).

\section{Basic Data and Clinical Data of Patients in the Abdominal Infection Complications Group and Nonabdominal Infection Complications Group}

There were 74 patients in the group of abdominal infection complications, including 17 patients with abdominal wall infection $(32.08 \%), 11$ patients with diffuse peritonitis (20.75\%), 20 patients with localized peritonitis (37.74\%), 7 patients with retroperitoneal abscess (13.21\%) and 19 patients with abdominal abscess $(35.85 \%)$. There were 36 males $(48.65 \%)$, and the average age was $44.84 \pm 11.94$ years in our study. In the nonabdominal infection group, 
Table 2 Risk Factors for IAH

\begin{tabular}{|c|c|c|c|c|c|}
\hline & All $(n=127)$ & Non-IAH Group $(n=67)$ & IAH Group $(n=60)$ & $\mathbf{T} / \mathbf{X} 2$ & $\mathbf{p}$ \\
\hline \multicolumn{6}{|l|}{ Abdominal wall tension decreased $(\mathrm{n}, \%)$} \\
\hline Mechanical ventilation & $25(19.69 \%)$ & $13(19.40 \%)$ & $12(20.00 \%)$ & 0.007 & 0.933 \\
\hline Laparotomy & $19(14.96 \%)$ & 5 (7.46\%) & 14 (23.33\%) & 6.2667 & $0.012 *$ \\
\hline Severe trauma & $23(18.11 \%)$ & II (16.42\%) & $12(20.00 \%)$ & 0.274 & 0.601 \\
\hline Obesity & 19 (14.96\%) & $6(9.00 \%)$ & $13(21.67 \%)$ & 4.020 & $0.045^{*}$ \\
\hline \multicolumn{6}{|l|}{ Intestinal contents increased } \\
\hline Gastroparesis & $22(17.32 \%)$ & $8(7.46 \%)$ & $14(23.33 \%)$ & 2.869 & 0.090 \\
\hline Intestinal obstruction & $20(15.75 \%)$ & 9 (I3.43\%) & II (I8.33\%) & 0.573 & 0.499 \\
\hline \multicolumn{6}{|l|}{ Abdominal contents increased } \\
\hline Ascites & $17(14.17 \%)$ & $9(13.43 \%)$ & $8(12.90 \%)$ & 0.000 & 0.987 \\
\hline Hepatic insufficiency with ascites & $23(18.11 \%)$ & $6(9.00 \%)$ & $17(28.33 \%)$ & 8.0148 & $0.005^{*}$ \\
\hline Cirrhosis with ascites & $10(7.87 \%)$ & $6(9.00 \%)$ & $4(6.67 \%)$ & 0.229 & 0.633 \\
\hline Other abdominal conditions of ascites & $25(19.69 \%)$ & $12(17.91 \%)$ & $13(21.67 \%)$ & 0.283 & 0.595 \\
\hline \multicolumn{6}{|c|}{ Capillary leakage or fluid resuscitation-related factors (n, \%) } \\
\hline Acidosis & $9(7.09 \%)$ & $5(7.46 \%)$ & $4(6.67 \%)$ & 0.031 & 0.861 \\
\hline Hypotension & $15(11.81 \%)$ & $3(4.48 \%)$ & $12(20.00 \%)$ & 7.322 & $0.007^{*}$ \\
\hline Hypothermia & $10(7.87 \%)$ & $7(10.45 \%)$ & $3(5.00 \%)$ & 1.295 & 0.255 \\
\hline Coagulation disorders & $9(7.09 \%)$ & $4(5.97 \%)$ & $5(8.33 \%)$ & 0.269 & 0.604 \\
\hline Massive fluid resuscitation & $31(24.40 \%)$ & $16(23.88 \%)$ & $15(25.00 \%)$ & 0.022 & 0.883 \\
\hline Oliguria & $29(22.83 \%)$ & 15 (22.39\%) & $14(23.33 \%)$ & 0.016 & 0.899 \\
\hline Sepsis & $30(23.62 \%)$ & $14(20.90 \%)$ & $16(26.67 \%)$ & 0.584 & 0.445 \\
\hline
\end{tabular}

Note: ${ }^{*}<0.05$.

Abbreviation: IAH, intra-abdominal hypertension.

Table 3 Fitting Linear Regression Model of AWTs of Points I-9, Mean AWT and IVP

\begin{tabular}{|c|c|c|}
\hline Location & AWT & Polynomial Regression Model \\
\hline Point l & $2.77 \pm 0.39$ & AWT $=-1.956 \times 10^{-3} I V P^{2}+8.899 \times 10^{-2} I V P+2.092, r=0.635(p<0.05)$ \\
\hline Point2 & $2.77 \pm 0.39$ & AWT $=-9.239 \times 10^{-4} I V P^{2}+6.556 \times 10^{-2} I V P+2.178, r=0.666(p<0.05)$ \\
\hline Point3 & $2.78 \pm 0.39$ & AWT $=-1.565 \times 10^{-3} I V P^{2}+7.927 \times 10^{-2} I V P+2.142, r=0.649(p<0.05)$ \\
\hline Point4 & $2.77 \pm 0.40$ & AWT $=-2.207 \times 10^{-3} I V P^{2}+9.675 \times 10^{-2} I V P+2.045, r=0.666(p<0.05)$ \\
\hline Point5 & $2.76 \pm 0.40$ & AWT $=-2.399 \times 10^{-3} I V P^{2}+1.044 \times 10^{-1} I V P+1.975, r=0.706(p<0.05)$ \\
\hline Point6 & $2.76 \pm 0.41$ & AWT $=-7.804 \times 10^{-4} I V P^{2}+6.431 \times 10^{-2} I V P+2.162, r=0.667(p<0.05)$ \\
\hline Point7 & $2.78 \pm 0.40$ & AWT $=-1.461 \times 10^{-3} I V P^{2}+8.135 \times 10^{-2} I V P+2.092, r=0.706(p<0.05)$ \\
\hline Point8 & $2.76 \pm 0.40$ & AWT $=-1.329 \times 10^{-3} I V P^{2}+7.740 \times 10^{-2} I V P+2.117, r=0.675(p<0.05)$ \\
\hline Point9 & $2.75 \pm 0.41$ & AWT $=-1.924 \times 10^{-3} I V P^{2}+9.110 \times 10^{-2} I V P+2.044, r=0.669(p<0.05)$ \\
\hline Mean & $2.77 \pm 0.38$ & AWT $=-1.616 \times 10^{-3} I V P^{2}+8.323 \times 10^{-2} I V P+2.094, r=0.706(p<0.05)$ \\
\hline
\end{tabular}

Abbreviations: AWT, abdominal wall tension; IVP, intravesical pressure.

there were 32 males $(60.38 \%)$, with an average age of $47.87 \pm 11.06$ years.

The average AWT of patients with abdominal infection complications was $2.85 \pm 0.33 \mathrm{~N} / \mathrm{mm}$ on the first day, which was higher than that of patients without abdominal infection complications $(2.63 \pm 0.40 \mathrm{~N} / \mathrm{mm})$ $(p<0.05)$. The mortality rate of the abdominal infection complication group was $34.25 \%$, which was higher than that of the nonabdominal infection complication group $(7.55 \%)(p<0.05)$. There were no significant 
A

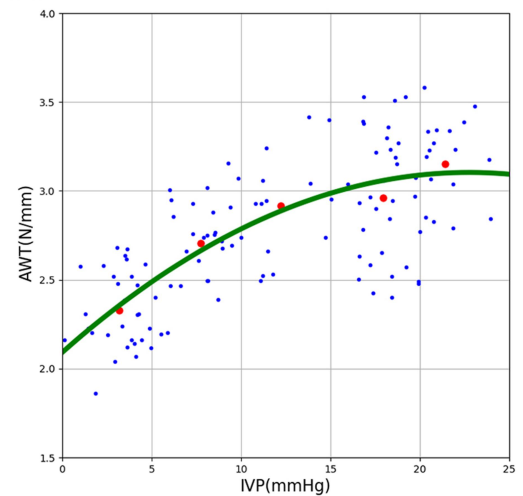

D

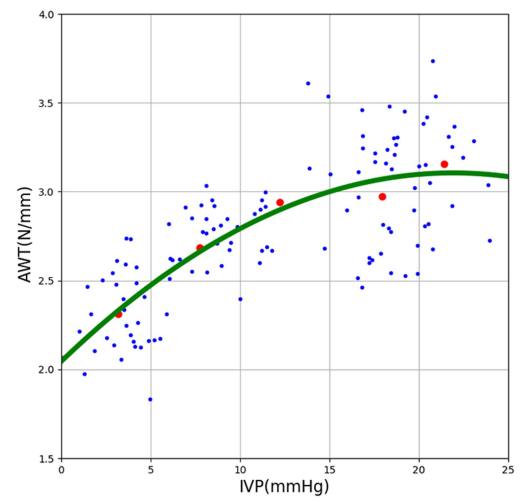

G

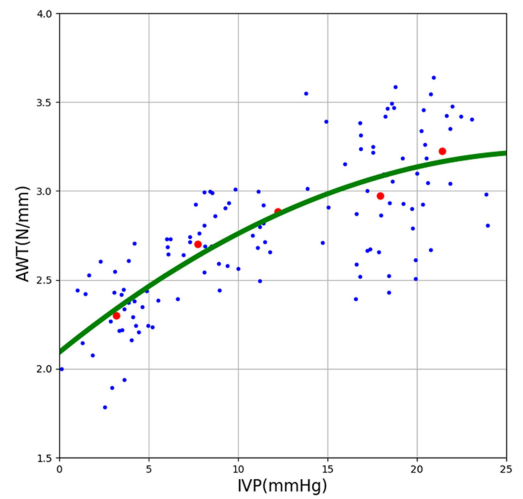

B

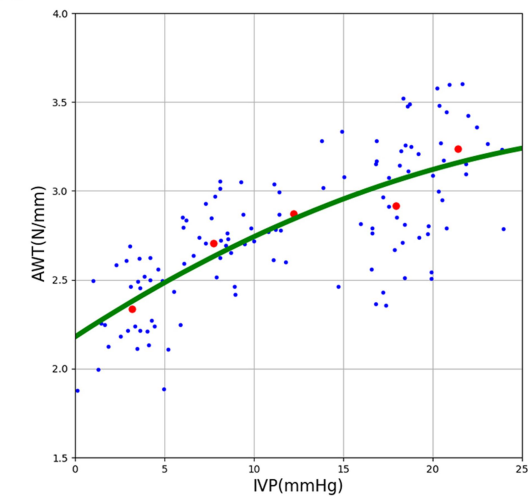

E

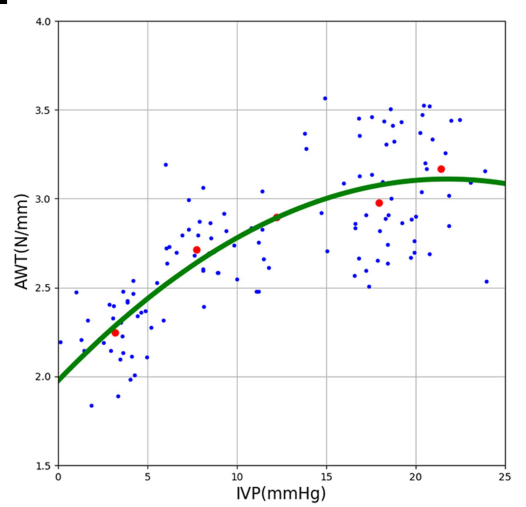

H

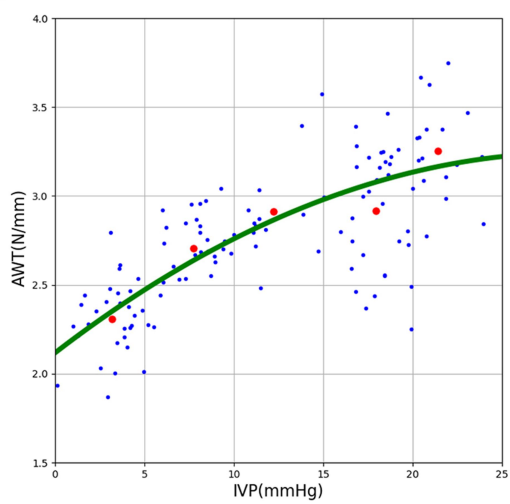

C

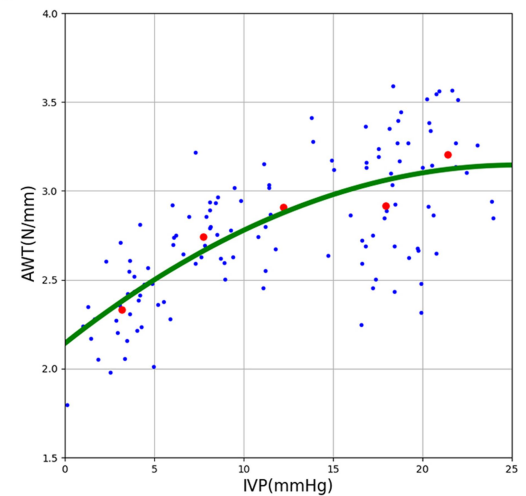

$\mathbf{F}$

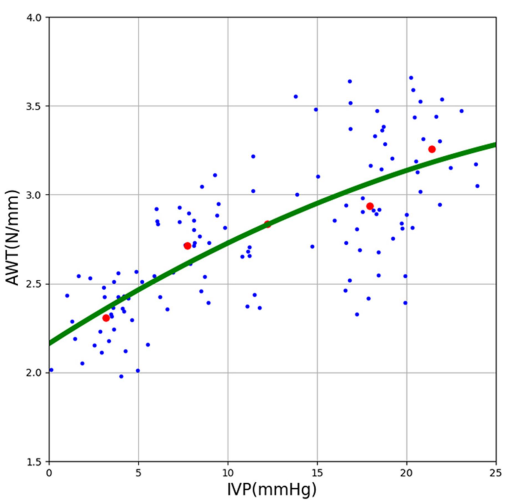

I

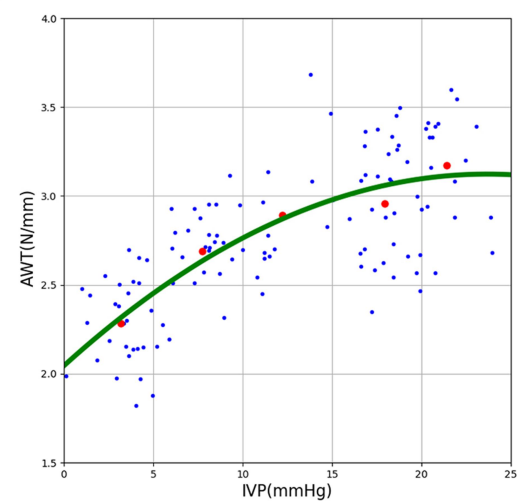

Figure 5 Polynomial regression model of AWT and IVP at 9 points on the abdominal wall. (A) Point I; (B) Point 2; (C) Point 3; (D) Point 4; (E) Point 5; (F) Point 6; (G) Point 7; (H) Point 8; (I) Point 9.

differences in other indexes between the two groups (see Table 4).

\section{Diagnostic Value of Different Indicators of Abdominal Infection Complications}

The best cutoff value of sensitivity and specificity of AWT in the diagnosis of abdominal complications was $2.57 \mathrm{~N} /$ $\mathrm{mm}$. AWT had the best efficacy in diagnosing abdominal complications, with an AUC of 0.677 , followed by AWT + IVP of 0.659 , IVP of 0.549 , and lactate of 0.490 (see Table 5 and Figure 7).

\section{Discussion}

In this study, we used a self-developed noninvasive tension measurement device and measured abdominal wall tension in critically ill patients for the first time 


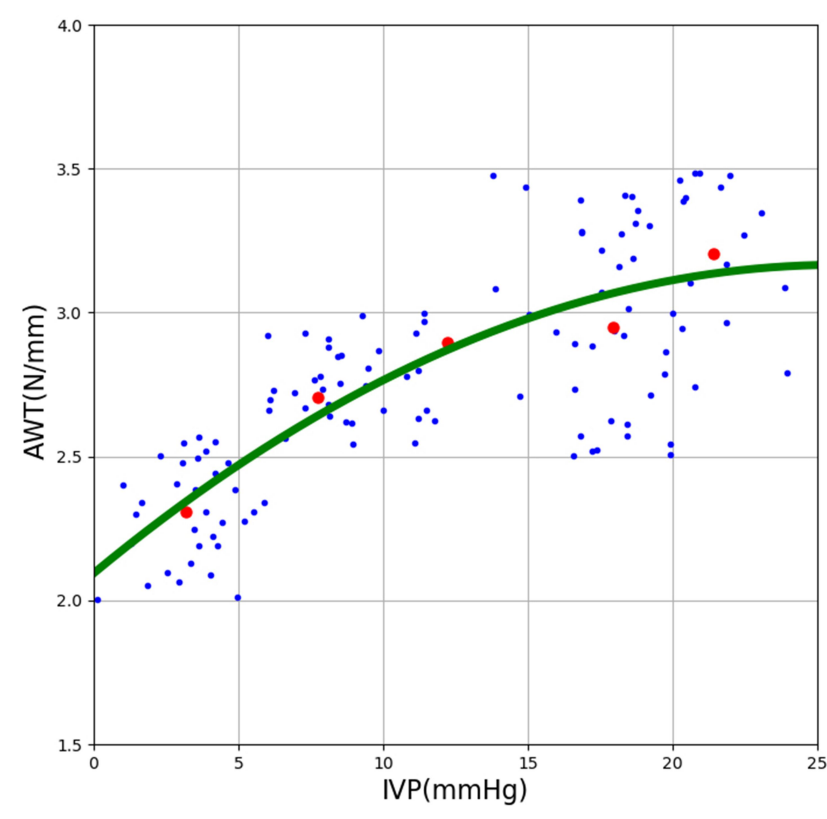

Figure 6 Polynomial regression model of mean AWT and IVP.

and found that AWT was positively correlated with IVP. It was further found that AWT was the most effective in diagnosing abdominal infection complications.

In the past few decades, increasing attention has been given to the pathophysiology, etiology, diagnosis and treatment of IAH and ACS. However, little attention has been given to the potential importance of $\mathrm{AC}$. $\mathrm{AC}$ is the degree of abdominal distension and the embodiment of the relationship between IAP and intra-abdominal volume (IAV) and plays an important role in understanding the effect of high IAV on IAP and peripheral organ perfusion., ${ }^{9,10,17}$ According to the pressure-volume curve of abdominal compliance, the abdominal wall constitutes the vast majority of the soft boundary of the abdominal cavity during the process of abdominal pressure rise, so AWT plays a decisive role in $\mathrm{AC}^{2,9}$

AWT describes the elastic properties of abdominal wall tissue, which are related to abdominal wall tension. Previous studies on the mechanics of abdominal wall muscles have shown that the parallel connection of abdominal wall muscles can enhance the strength and rigidity of muscle layers. $^{8,14,18}$ At the same time, many studies have also proven that adjacent skeletal muscles of mammals transmit parallel forces through connective tissue networks. Jensen et $\mathrm{al}^{19}$ theoretically described the potential of the connective tissue network in inhibiting the lateral expansion of muscles during contraction, thus enhancing the effective stiffness and strength of muscles. The mechanical and anatomical characteristics of the abdominal wall muscles and connective tissue seem to be particularly suitable for this tension, stiffness and strengthening effect. AWT can help us to further understand the relationship between IAP and IAV. At the same time, it can serve as a supplement to the measurement method of intravesical pressure. It can be used as a means to infer the intra-abdominal pressure and evaluate the abdominal condition in patients with neurogenic bladder, bladder rupture and bladder compressed by pelvic hematoma, for whom intravesical pressure cannot be measured.

The physics principle that underlies the relationship between AWT and IVP is based on the famous Laplace Law. The Laplace Law was discovered by Pierre Simon de Laplace, a French scientist, and describes the relationship among the wall tension, pressure and radius of a vessel. ${ }^{6,20}$ This formula is often used in medical physiology and rehabilitation medicine, helping us understand many common clinical pathophysiological mechanisms, such as erection of the penis, uterine delivery, compartment syndrome, and peripheral edema and can also help us carry out several medical operations, such as promoting bladder emptying, lumbosacral orthosis, laparoscopic surgery, edema control, etc. 6,20,21 In addition, the "gold standard" of measuring the intra-abdominal pressure by measurement of intravesical pressure is also based on this principle. $^{5,22}$ The accurate assessment of abdominal compliance is mainly calculated by the Laplace Law, that is, pressure $=(2 \times$ thickness $\times$ tension $) /$ radius. According to the Laplace Law, the greater the wall pressure and radius are, the greater the wall tension will be. For spheres with constant pressure, the wall tension depends on its thickness. If the abdominal cavity is considered a cylindrical pressure vessel (abdominal wall thickness $<$ radius/4), the abdominal wall tension $=$ (external pressure - internal pressure) radius/abdominal wall thickness. ${ }^{9,13,20}$

Our results are similar to those of some previous studies. In the pre-experiment of van Ramhorst et $\mathrm{al}^{23}$ in 2008, the AWT of 7 points on the abdominal wall of 2 corpses was measured by noninvasive AWT measurement equipment with a tensiometer for the first time. They found that AWT was significantly correlated with IAP, and the correlation between AWT in the middle abdomen and IAP was better. In a subsequent study, van Ramhorst et $\mathrm{al}^{24}$ used the same noninvasive AWT measurement equipment with a pressure and displacement sensor to measure the AWT at 6 points in the abdomen of 14 corpses under different abdominal pressures and the AWT of 42 
Table 4 Basic Data and Clinical Data of Patients in the Nonabdominal Infection Group and Abdominal Infection Group

\begin{tabular}{|l|l|l|l|l|}
\hline & Nonabdominal Infection Group $(\mathbf{n = 5 3})$ & Abdominal Infection Group (n=74) & $\mathbf{T} / \mathbf{X 2}$ & $\mathbf{P}$ \\
\hline Male $(\mathrm{n}, \%)$ & $32(60.38 \%)$ & $36(48.65 \%)$ & 1.708 & 0.191 \\
\hline Age (years) & $47.87 \pm 11.06$ & $44.84 \pm 11.94$ & 1.450 & 0.149 \\
\hline BMI $\left(\mathrm{kg} / \mathrm{m}^{2}\right)$ & $25.31 \pm 2.68$ & $24.67 \pm 2.40$ & 1.410 & 0.161 \\
\hline APACHE II score & $17.94 \pm 4.95$ & $18.14 \pm 4.99$ & -0.220 & 0.825 \\
\hline SOFA score & $5.15 \pm 1.69$ & $5.38 \pm 1.72$ & -0.740 & 0.460 \\
\hline ISS for trauma patients $(\mathrm{n}=3 \mathrm{I})$ & $21.27 \pm 8.76$ & $23.50 \pm 5.29$ & -0.890 & 0.383 \\
\hline
\end{tabular}

Complications of abdominal infection

\begin{tabular}{|c|c|c|c|c|}
\hline Infection of abdominal wall & 0 & 17 & & \\
\hline Diffuse peritonitis & 0 & II & & \\
\hline Localized peritonitis & 0 & 20 & & \\
\hline Retroperitoneal abscess & 0 & 7 & & \\
\hline Abdominal abscess & 0 & 19 & & \\
\hline PCT $(\mu g / L)$ & $5.40 \pm 2.78$ & $5.87 \pm 2.91$ & -0.910 & 0.367 \\
\hline Lac (mmol/L) & $3.8 I \pm 2.34$ & $3.79 \pm 2.4 I$ & 0.060 & 0.954 \\
\hline CRP (mg/L) & $10.62 \pm 5.52$ & $10.21 \pm 5.47$ & 0.410 & 0.682 \\
\hline AWT (N/mm) & $2.63 \pm 0.40$ & $2.85 \pm 0.33$ & -3.210 & $0.00 I^{*}$ \\
\hline IVP (mmHg) & $11.09 \pm 7.66$ & $13.18 \pm 6.42$ & -1.670 & 0.098 \\
\hline Length of ICU stay (days) & $7.49 \pm 3.30$ & $7.93 \pm 3.60$ & -0.710 & 0.482 \\
\hline Length of hospital stay (days) & $16.17 \pm 5.26$ & $15.24 \pm 4.62$ & 1.050 & 0.295 \\
\hline ICU death rate $(n, \%)$ & $4(7.55 \%)$ & 25 (34.25\%) & 12.064 & $0.001 *$ \\
\hline
\end{tabular}

Note: ${ }^{*}<<0.05$.

Abbreviations: BMI, Body mass index; APACHE, Acute Physiology, Age, Chronic Health Evaluation; SOFA, Sequential organ failure; ISS, Injury severity score; PCT, Procalcitonin; Lac, Lactate acid; CRP, C-reaction protein; AWT, Abdominal wall tension; IVP, intravesical pressure; ICU, Intensive care unit.

Table 5 Diagnostic Value of Different Indicators of Abdominal Complications

\begin{tabular}{|l|l|l|l|l|}
\hline & Specificity & Sensitivity & $\begin{array}{l}\text { Negative } \\
\text { Predictive } \\
\text { Value }\end{array}$ & $\begin{array}{l}\text { Positive } \\
\text { Predictive } \\
\text { Value }\end{array}$ \\
\hline AWT & 50.94 & 83.78 & 69.23 & 70.45 \\
IVP & 58.49 & 51.35 & 46.27 & 63.33 \\
Lac & 13.21 & 95.95 & 70.00 & 60.68 \\
AWT & 64.15 & 48.65 & 47.22 & 65.45 \\
+IVP & & & & \\
\hline
\end{tabular}

Abbreviations: AWT, Abdominal wall tension; IVP, intravesical pressure; Lac, Lactate acid.

healthy volunteers in supine, sitting and standing positions. The researchers found a significant correlation between AWT and IAP. During the Valsalva maneuver,
AWT increased in both expiration and inspiration. AWT in the standing position was the highest, followed by the supine position and sitting position, with average AWTs of 1.36, 1.18 and $1.06 \mathrm{~N} / \mathrm{mm}$, respectively. In 2015, Chen et $\mathrm{al}^{25}$ measured the AWT of 51 patients with selfdeveloped tensiometer-type AWT measurement equipment and found that AWT and IVP had significant correlations ( $\mathrm{r}=0.986, p<0.01)$, and the regression equation was $\mathrm{Y}=-1.369+9.57 \mathrm{X}(p<0.01)$. Different breathing states and positions have effects on AWT. The results of previous studies are similar to our study; both found that AWT and IAP are related. Previous studies have used linear regression or least squares to analyze the relationship between AWT and IAP, but its limitation is that it can be applied only to data with a linear relationship. 


\section{ROC Curve}

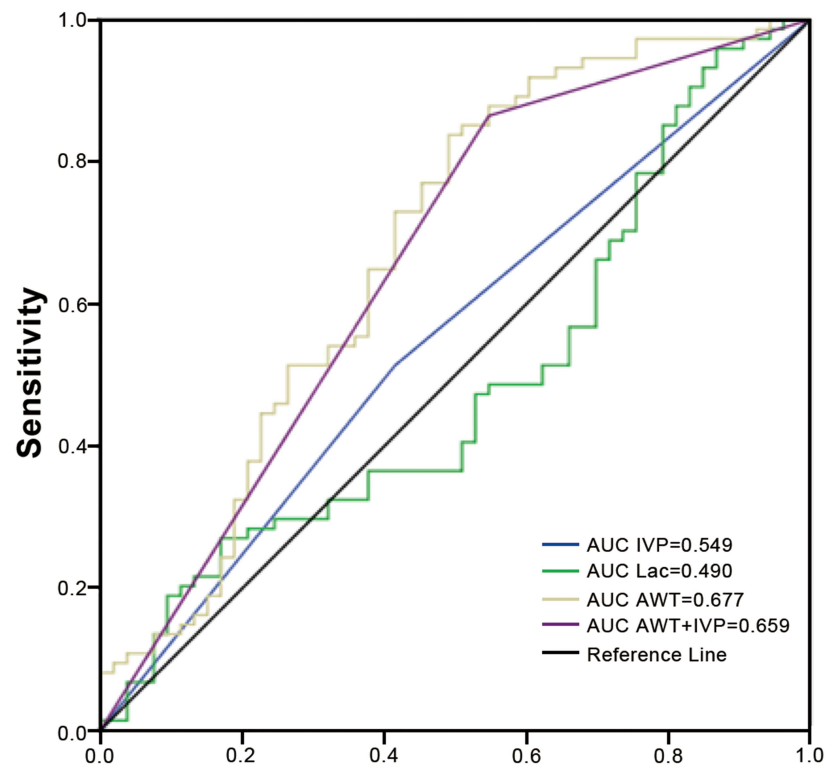

Figure 7 Diagnostic value of different indicators of abdominal complications.

However, considering the complexity of the actual clinical situation, the relationship between AWT and IVP may be nonlinear. ${ }^{17,26,27}$ Based on previous research, we first innovatively clustered the five regions divided by IVP to obtain the cluster center, which is the red dot, and then used polynomial regression and a quadratic function determine the fit. To the best of our knowledge, this is the first practical application of abdominal wall tension measurement and IVP measurement performed in clinical cases. This approach has remarkably discovered interesting changes in the correlation between different IVP intervals and AWT. We will further observe and discuss our approach and findings in ongoing work and look forward to interpreting their clinical significance.

In the studies of van Ramshorst et $\mathrm{al}^{23,24}$ in 2008 and 2010, a total of 6 points in the mid-abdomen and left abdomen were selected as AWT measurement points. Three measurement points were located on the midline of the abdomen, and three measurement points were located on the left abdomen, including point 1 ( $5 \mathrm{~cm}$ below the xiphoid process), point 2 ( $5 \mathrm{~cm}$ above the belly button), point $3(5 \mathrm{~cm}$ to the left of point 2), point 4 (10 $\mathrm{cm}$ to the left of point 2$)$, point $5(5 \mathrm{~cm}$ above the symphysis pubis), and point $6(5 \mathrm{~cm}$ to the left of point 5).Considering that there may be differences in AWT between the left and right abdominal measurement points, three measurements were taken on the right and left abdomen, including point $7(5 \mathrm{~cm}$ to the right of point 2$)$, point $8(10 \mathrm{~cm}$ to the right of point 2) and point $9(5 \mathrm{~cm}$ to the right of point 5). As the operation is relatively cumbersome, reducing the measurement points and simplifying and standardizing the measurement method are the directions of future efforts of our research group. Based on previous studies, our study standardized AWT, determined the specific cutoff value, and further analyzed its clinical application in abdominal infectious diseases. However, the cutoff value for the diagnosis of abdominal cavity infection in our study is only a preliminary conclusion based on the experimental design and statistical results, and further clinical verification is needed in future work. When we performed AWT measurement, all patients were in a quiet state. Pressing the abdomen may cause peritoneal irritation in patients, which will have a certain impact on AWT measurement. However, peritoneal irritation is an important clinical sign of abdominal infection. There have been no previous studies on the quantitative evaluation of peritoneal irritation. We hope to provide a method to quantify abdominal muscle tension in peritoneal irritation by measuring AWT to provide a new means for the diagnosis of peritonitis.

In 2013, Mulier et al ${ }^{26}$ studied the risk factors for AWT in 70 patients undergoing laparoscopic surgery and found that age was positively correlated with abdominal wall elasticity. In theory, a low AWT should be expected to appear in young athletes with strong abdominal muscles, which conforms to the authors' personal experience but lacks further data support. Sugerman et $\mathrm{al}^{27,28}$ compared the IAP of obese patients with that of nonobese patients and found that the IAP of obese patients was higher than that of nonobese patients. The study by Wilson et al $^{29}$ also reached the same conclusion. Our study also found that among patients with IAH, the number of patients with BMI $>25 \mathrm{~kg} / \mathrm{m}^{2}$ was higher, consistent with previous researchers' conclusions. However, subcutaneous fat in obese patients is considered to have a negative effect on the elastic properties of the abdominal wall. Perhaps because the muscle layer plays a major role in the AWT, the AWT is not directly related to the degree of obesity but has individual differences. ${ }^{21}$ The reason for the higher AWT in obese patients might be related to the reduction in shaping ability caused by high IAV and the increase in IAP in the resting state caused by gravity of the abdominal wall, and no correlation between the thickness of the rectus abdominis and $\mathrm{AC}$ was found in obese patients. ${ }^{30}$ In contrast, the possibility that patients with less fat may exercise more abdominal muscles and have a higher AWT cannot be ruled out.

AWT is most commonly associated with some surgical diseases. Noninvasive AWT measurement can be used as a predictive or diagnostic tool for potential abdominal 
surgical diseases. Burning of the abdominal wall and subsequent surgical treatment will change the abdominal wall structure and reduce AWT. ${ }^{31}$ Hakobyan and Mkhoyan ${ }^{32}$ found that the abdominal muscles relaxed and AWT decreased during epidural anesthesia in critically ill patients with primary ACS after surgery or trauma. IAP decreased from $16.8 \mathrm{mmHg}$ to $6.3 \mathrm{mmHg}$, and intra-abdominal perfusion pressure increased from $60.2 \mathrm{mmHg}$ to $76.1 \mathrm{mmHg}$. The use of adhesive tape, banding or retention sutures during surgical operation can increase AWT without changing the abdominal wall structure, but it may increase IAP, increasing the risk of adverse incision complications. ${ }^{33}$ During laparoscopic surgery, abdominal inflation will raise the abdominal wall. The increased IAV is called the laparoscopic workspace. However, patients with reduced AWT risk factors (eg, obesity, previous pregnancy, history of abdominal surgery) may have a risk of abdominal hypertension. Research on AWT and abdominal wall function is mostly related to ventral incisional hernia. Ventral incisional hernia (VIH) is most commonly seen in patients undergoing laparotomy, and the incidence rate is approximately $11 \%-23 \% .{ }^{19}$ Incisional hernia can cause pain, reduce quality of life, and even lead to strangulated intestinal obstruction and poor wound healing. The pathogenesis of incisional hernia may be related to AWT. When the AWT decreases, abdominal pressure increases beyond the tolerance range of the AWT, and the hernia protrudes from the weak abdominal wall. ${ }^{34,35}$ Hernia repair surgery can cause abdominal wall rigidity and reduce AWT. BuenoLledo et $\mathrm{al}^{36}$ adopted preoperative intra-abdominal muscle injection with creotoxin to reduce AWT and improve the success rate of large incisional hernia surgery. Therefore, preoperative assessment of the AWT could be an effective tool for identifying patients at high risk of IAH.

In conclusion, the noninvasive AWT measurement method has a good correlation with IAP and is a fast, low-cost and well-correlated noninvasive diagnostic method that may be used as a new clinical diagnostic method for abdominal diseases.

\section{Limitations}

Only a few patients were included in this study, and analysis of risk factors for patients with high AWT was not carried out. Therefore, large-sample, multicenter clinical trials and relevant clinical studies of AWT under different physiological or disease states are needed.

\section{Acknowledgment}

We would like to share our individual deidentified participant data forever. We also intend to share the data about the AWT measuring equipment. Since some research work of AWT is ongoing, if other researchers would like access to our data, they can email the corresponding author (Email:hpzhangly@163.com). We also welcome researchers to participate in our multi-center clinical studies work.

\section{Funding}

Clinical Technology Innovation and Cultivation Project of Army Medical University (Project No. cx2019js109); General Project of Chongqing Special Project of Technology Innovation and Application Development (research on abdominal wall tension measurement method establishment and clinical application: cstc2019jscxmsxmx0240).

\section{Disclosure}

There are no conflicts of interest to declare.

\section{References}

1. Malbrain ML, Cheatham ML, Kirkpatrick A, et al. Results from the International Conference of experts on intra-abdominal hypertension and abdominal compartment syndrome. I. definitions. Intensive Care Med. 2006;32(11):1722-1732. doi:10.1007/s00134-006-0349-5

2. Kirkpatrick AW, Roberts DJ, De Waele J, et al. Intra-abdominal hypertension and the abdominal compartment syndrome: updated consensus definitions and clinical practice guidelines from the World Society of the Abdominal Compartment Syndrome. Intensive Care Med. 2013;39(7):1190-1206. doi:10.1007/s00134-013-2906-z

3. Malbrain ML, Chiumello D, Cesana BM, et al. A systematic review and individual patient data meta-analysis on intra-abdominal hypertension in critically ill patients: the wake-up project. World initiative on Abdominal Hypertension Epidemiology, a Unifying Project (WAKE-Up!). Minerva Anestesiol. 2014;80(3):293-306.

4. Kirkpatrick AW, Sugrue M, McKee JL, et al. Update from the Abdominal Compartment Society (WSACS) on intra-abdominal hypertension and abdominal compartment syndrome: past, present, and future beyond Banff 2017. Anaesthesiol Intensive Ther. 2017;49 (2):83-87. doi:10.5603/AIT.a2017.0019

5. Balogh Z, De Waele JJ, Malbrain ML. Continuous intra-abdominal pressure monitoring. Acta Clin Belg. 2007;62(Suppl 1):26-32. doi:10.1179/acb.2007.62.s1.005

6. De Waele JJ, De laet I, Malbrain ML. Rational intraabdominal pressure monitoring: how to do it? Acta Clin Belg. 2007;62(Suppl 1):16-25. doi:10.1179/acb.2007.62.s1.004

7. Ferreira PH, Ferreira ML, Maher CG, Refshauge K, Herbert RD, Hodges PW. Changes in recruitment of transversus abdominis correlate with disability in people with chronic low back pain. $\mathrm{Br} J$ Sports Med. 2010;44(16):1166-1172. doi:10.1136/bjsm.2009.061515

8. Brown SH. Mechanically relevant consequences of the composite laminate-like design of the abdominal wall muscles and connective tissues. Med Eng Phys. 2012;34(4):521-523. doi:10.1016/j. medengphy.2011.11.008 
9. Malbrain ML, De Laet I, De Waele JJ, et al. The role of abdominal compliance, the neglected parameter in critically ill patients a consensus review of 16. Part 2: measurement techniques and management recommendations. Anaesthesiol Intensive Ther. 2014;46(5):406-432. doi:10.5603/AIT.2014.0063

10. Malbrain ML, Roberts DJ, De Laet I, et al. The role of abdominal compliance, the neglected parameter in critically ill patients a consensus review of 16. Part 1: definitions and pathophysiology. Anaesthesiol Intensive Ther. 2014;46(5):392-405. doi:10.5603/ AIT.2014.0062

11. Sugrue M, Bauman A, Jones F, et al. Clinical examination is an inaccurate predictor of intraabdominal pressure. World J Surg. 2002;26(12):1428-1431. doi:10.1007/s00268-002-6411-8

12. Reuben A. Examination of the abdomen. Clin Liver Dis (Hoboken). 2016;7(6):143-150. doi:10.1002/cld.556

13. Tayebi S, Gutierrez A, Mohout I, et al. A concise overview of non-invasive intra-abdominal pressure measurement techniques: from bench to bedside. J Clin Monit Comput. 2020;35(1):51-70. doi:10.1007/s10877-020-00561-4

14. Bilezikian JA, Faulkner JD, Fox SS, Hooks W, Hope WW. Clinical application of the measurement of abdominal wall tension in Hernia repair. Surg Technol Int. 2019;35:129-134.

15. Dellinger RP, Levy MM, Rhodes A, et al. Surviving Sepsis Campaign: international guidelines for management of severe sepsis and septic shock, 2012. Intensive Care Med. 2013;39(2):165-228.

16. Sartelli M, Catena F, Abu-Zidan FM, et al. Management of intra-abdominal infections: recommendations by the WSES 2016 consensus conference. World J Emerg Surg. 2017;12:22.

17. Blaser AR, Bjorck M, De Keulenaer B, Regli A. Abdominal compliance: a bench-to-bedside review. J Trauma Acute Care Surg. 2015;78(5):1044-1053. doi:10.1097/TA.0000000000000616

18. Konerding MA, Chantereau P, Delventhal V, Holste JL, Ackermann M. Biomechanical and histological evaluation of abdominal wall compliance with intraperitoneal onlay mesh implants in rabbits: a comparison of six different state-of-the-art meshes. Med Eng Phys. 2012;34(7):806-816. doi:10.1016/j.medengphy.2011.09. 022

19. Jensen KK, Kjaer M, Jorgensen LN. Abdominal muscle function and incisional hernia: a systematic review. Hernia. 2014;18(4):481-486. doi:10.1007/s10029-014-1242-8

20. Basford JR. The Law of Laplace and its relevance to contemporary medicine and rehabilitation. Arch Phys Med Rehabil. 2002;83 (8):1165-1170. doi:10.1053/apmr.2002.33985

21. Sugerman H, Windsor A, Bessos M, Wolfe L. Intra-abdominal pressure, sagittal abdominal diameter and obesity comorbidity. J Intern Med. 1997;241(1):71-79. doi:10.1046/j.1365-2796.1997.89104000.x

22. Rajasurya V, Surani S. Abdominal compartment syndrome: often overlooked conditions in medical intensive care units. World J Gastroenterol. 2020;26(3):266-278. doi:10.3748/wjg.v26.i3.266

23. van Ramshorst GH, Lange JF, Goossens RH, et al. Non-invasive measurement of intra-abdominal pressure: a preliminary study. Physiol Meas. 2008;29(8):N41-N47. doi:10.1088/0967-3334/29/8/N01
24. van Ramshorst GH, Salih M, Hop WC, et al. Noninvasive assessment of intra-abdominal pressure by measurement of abdominal wall tension. J Surg Res. 2011;171(1):240-244. doi:10.1016/j.jss.2010. 02.007

25. Chen YZ, Yan SY, Chen YQ, et al. Noninvasive monitoring of intra-abdominal pressure by measuring abdominal wall tension. World J Emerg Med. 2015;6(2):137-141. doi:10.5847/wjem.j.19208642.2015.02.009

26. Mulier JP, Dillemans B, Van Cauwenberge S. Impact of the patient's body position on the intraabdominal workspace during laparoscopic surgery. Surg Endosc. 2010;24(6):1398-1402. doi:10.1007/s00464009-0785-8

27. Sugerman H, Windsor A, Bessos M, Kellum J, Reines H, DeMaria E. Effects of surgically induced weight loss on urinary bladder pressure, sagittal abdominal diameter and obesity co-morbidity. Int $J$ Obes Relat Metab Disord. 1998;22(3):230-235. doi:10.1038/sj.ijo.0800574

28. Sugerman HJ. Effects of increased intra-abdominal pressure in severe obesity. Surg Clin North Am. 2001;81(5):1063-1075, vi. doi:10.1016/ S0039-6109(05)70184-5

29. Wilson A, Longhi J, Goldman C, McNatt S. Intra-abdominal pressure and the morbidly obese patients: the effect of body mass index. J Trauma. 2010;69(1):78-83. doi:10.1097/TA.0b013e3181e05a79

30. Lambert DM, Marceau S, Forse RA. Intra-abdominal pressure in the morbidly obese. Obes Surg. 2005;15(9):1225-1232. doi:10.1381/ 096089205774512546

31. Tsoutsos D, Rodopoulou S, Keramidas E, Lagios M, Stamatopoulos K, Ioannovich J. Early escharotomy as a measure to reduce intraabdominal hypertension in full-thickness burns of the thoracic and abdominal area. World J Surg. 2003;27 (12):1323-1328. doi:10.1007/s00268-003-6962-3

32. Hakobyan RV, Mkhoyan GG. Epidural analgesia decreases intraabdominal pressure in postoperative patients with primary intra-abdominal hypertension. Acta Clin Belg. 2008;63(2):86-92. doi:10.1179/acb.2008.63.2.005

33. Zhang HY, Liu D, Tang H, et al. The effect of different types of abdominal binders on intra-abdominal pressure. Saudi Med J. 2016;37(1):66-72. doi:10.15537/smj.2016.1.12865

34. Kirkpatrick AW, Nickerson D, Roberts DJ, et al. Intra-abdominal hypertension and abdominal compartment syndrome after abdominal wall reconstruction: quaternary syndromes? Scand J Surg. 2017;106 (2):97-106. doi:10.1177/1457496916660036

35. Feng MP, Baucom RB, Broman KK, et al. Early repair of ventral incisional hernia may improve quality of life after surgery for abdominal malignancy: a prospective observational cohort study. Hernia. 2019;23(1):81-90. doi:10.1007/s10029-018-1863-4

36. Bueno-Lledo J, Torregrosa A, Ballester N, et al. Preoperative progressive pneumoperitoneum and botulinum toxin type $\mathrm{A}$ in patients with large incisional hernia. Hernia. 2017;21(2):233-243. doi:10.10 07/s10029-017-1582-2
Medical Devices: Evidence and Research

\section{Publish your work in this journal}

Medical Devices: Evidence and Research is an international, peerreviewed, open access journal that focuses on the evidence, technology, research, and expert opinion supporting the use and application of medical devices in the diagnosis, monitoring, treatment and of medical devices in the diagnosis, monitoring, treatment and
management of clinical conditions and physiological processes. The identification of novel devices and optimal use of existing devices which will lead to improved clinical outcomes and more effective patient management and safety is a key feature of the journal. The manuscript management system is completely online and includes a very quick and fair peer-review system. Visit http:// www.dovepress.com/testimonials.php to read real quotes from published authors. 